\title{
"NO HAN AUCTORIDAD DE DOCTRINA»: ALFONSO DE CARTAGENA Y SUS IDEAS SOBRE LA TRAGEDIA Y SU TRANSMISIÓN*
}

\author{
Tomàs Martínez Romero \\ Universitat Jaume I \\ tomas.martinez@fil.uji.es
}

Cualquier lector o estudioso de la difusión medieval de las obras de Séneca en Castilla ${ }^{1}$ se puede preguntar por qué, hasta donde sabemos, Alfonso de Cartagena no tuvo nunca la intención de traducir las Tragedias o al menos de extraer de ellas una cantidad respetable de materiales, más allá de algunas referencias y citas que introdujo en unas cuantas glosas marginales ${ }^{2}$.

\footnotetext{
* Este trabajo se publica en colaboración con el proyecto de investigación Alfonso de Cartagena. Obras Completas FFI 2014-55902-P y FFI 2017-84858-P (MINECO y MICINN, Gobierno de España).

${ }^{1}$ Véase, en general, la imprescindible aportación de Karl Alfred Blüher, Séneca en España. Investigaciones sobre la recepción de Séneca en España desde el siglo XIII hasta el siglo XVII, Madrid, Gredos, 1983 [original en alemán, 1969]. Para las traducciones ibéricas medievales de Séneca, remito a los numerosos trabajos de Andrea Zinato, en concreto a «Le traduzioni catalane di opere di Seneca e loro influsso sulle traduzioni castigliane», en La cultura catalana tra l'Umanesimo e il Barocco. Atti del V convegno dell'Associazione Italiana di Studi Catalani, ed. de C. Romero y R. Arqués, Padova, Programma,1994, pp. 175-184, y «Séneca en España», en prensa. Un magnífico estado de la cuestión ofrece Elisa Ruiz García, «En torno a los romanceamientos de Séneca en el Cuatrocientos», en Seneca: una vicenda testuale, ed. de T. De Robertis y G. Resta, Firenze, Mandragora, 2004, pp. 65-82. Sobre las Tragedias, conviene consultar la tesis doctoral de Emilio del Río Sanz, La influencia del teatro de Séneca en la literatura española, Logroño, 1995 (en microfichas); N. G. Round, «Las traducciones medievales, catalanas y castellanas, de las Tragedias de Séneca», en Anuario de Estudios Medievales, 9 (1974-79), pp. 187-227; Giuseppina Grespi, La traduzione castigliana medievale della 'Medea' di L. A. Seneca, Viareggio-Lucca, Mauro Baroni editore, 2005. Para la difusión de Séneca en catalán, Tomàs Martínez Romero, Un clàssic entre clàssics. Sobre traduccions i recepcions de Sèneca a l'època medieval, Barcelona-Valencia, Publicacions de l'Abadia de Montserrat-Institut Interuniversitari de Filologia Valenciana, 1998.

${ }^{2}$ Así se hace en Tomàs Martínez Romero, «The Reception of Seneca in the Crowns of Aragon and Castile in the Fourteenth and Fifteenth Centuries», en Brill's Companion to the Reception of Senecan Tragedy. Scholarly, Theatrical and Literary Receptions, ed. de Eric Dodson-Robinson, Leiden- Boston, Brill, 2016, pp. 101-121, p. 109. Sobre Cartagena y su obra, véase M. ${ }^{a}$ Morrás, «Alfonso de Cartagena», en Diccionario filológico de la literatura española medieval (Textos y transmisión), coord. de C. Alvar y J. M. Lucía Megías, Madrid, Castalia, 2009, pp. 93-127. Sí que se benefició abundantemente de la correspondiente traducción catalana el autor del Tirant lo Blanc, por ejemplo (J. Pujol, «El desenllaç tràgic
} 
Resulta extraño, en efecto, que este prolífico traductor no hubiese tenido la tentación de aventurarse en tales trabajos. En principio, tampoco se puede alegar desconocimiento: sabemos de la presencia del texto latino en tierras hispánicas como mínimo desde el siglo $\mathrm{XIV}^{3}$, pese a que las obras filosóficas y morales del autor hispanolatino tuvieron más temprana y mucho mejor difusión. Quizás las finalidades político-educativas de sus versiones senequistas, realizadas fundamentalmente en la década de 1430, podrían excusar esta laguna. Y sin embargo, esa misma extrañeza debieron de tener los mismos contemporáneos, hasta el extremo de que alguno le asignó una versión de las Tragedias, aun a sabiendas de su inexistencia. En efecto, Diego Rodríguez de Almela, paje y familiar de Cartagena, no tuvo inconveniente en introducir la obra entre las versiones realizadas por su maestro. En el Valerio de las historias, afirma que «tornó de latín en nuestra lengua vulgar [...] dos libros de Providencia, [...] otros dos de Clemencia, [...] otro llamado las Tragedias, [...] y en fin las Epístolas que embió a Sant Pablo, y otras muchas que embió a Lucilo, su amigo y a otros». Rodríguez de Almela, no cabe duda, le asignó la traducción del corpus de Séneca conocido y a él atribuido entonces. Poco importaba que supiese -él y bastantes de sus lectores-que las Tragedias y las Epistolas a Lucilio andaban traducidas anónimamente y que los Proverbia habían sido versionados veinte años antes por Pero Díaz de Toledo ${ }^{4}$.

del Tirant lo Blanc: les Troianes de Sèneca i les idees de tragèdia al segle XV», en Boletín de la Real Academia de Buenas Letras de Barcelona, 45 (1995), pp. 29-66). Aunque brevemente, J. Fernández López, «Humanismo y comentario en la Castilla del siglo xv: Juan de Mena y Alonso de Cartagena», en Minerva, 24 (2011), pp. 17-30, muestra el aprovechamiento moral, no simbólico, que realiza Cartagena del texto dramático de Séneca, en una dirección más «profesional» que literaria, lo que determina su lectura.

${ }^{3}$ Conocemos manuscritos de origen hispánico desde mucho antes de que Cartagena comenzara su labor traductora. Para la tradición manuscrita de la obra, consúltese G. Brugnoli, «La tradizione manoscritta di Seneca tragico alla luce delle testimonianze medioevali», en Atti della Accademia Nazionale dei Lincei. Classe di Scienze morali, storiche e filologiche. Memorie, 8:3 (1957), pp. 201-287; R. H. Philp, «The manuscript tradition of Seneca's Tragedies», en The Classical Quartely, 18 (1968), pp. 150-179. Aún conviene ojear el clásico libro de L. Rubio Fernández, Catálogo de los manuscritos clásicos latinos existentes en España, Madrid, Universidad Complutense, 1984.

${ }^{4}$ Más taxativo es N. G. Round, «Alonso de Cartagena’s Libros de Séneca: Disentangling the Manuscript Tradition», en Medieval Spain: Culture, Conflict and Coexistence. Studies in Honour of Angus Mackay, ed. de R. Collins y A. Goodman, Basingstoke (Hampshire)-New York, Palgrave Macmillan, 2002, pp. 123-147, p. 127: «Nobody in the fifteenth century, however, credited Cartagena with the translation of the Proverbia, Tragedies, or Letters, let alone any commentaries on Livy». Sobre los Proverbia, véase N. G. Round, «The Mediaeval Reputation of the Proverbia Senecae: A Partial Survey Based on Recorded Mss.», en Proceedings of the Royal Irish Academy, 72, C, 5 (1972), pp. 103-151. Y sobre la traducción de Díaz de Toledo: Laurette Godinas, «Entre la libertad de la tradición sapiencial y el respeto hacia las autoridades: la edición crítica de los Proverbios de Séneca traducidos y glosados por Pero Díaz de Toledo», en Actas del XV Congreso de la Asociación Internacional de Hispanistas, ed. de B. Mariscal y A. González, México D. F., Fondo de Cultura Económica, 2007, vol. 1, pp. 351-362; y Godinas, «La tradición textual de los Proverbios de Séneca», en Aliento, 5 (= Los 'Proverbia' Senecae: La traversée européenne des Proverbia Senecae: de Publilius Syrus à Erasme et au-delà, coord. por Marta López Izquierdo, ed. de 
Ciertamente, los versos trágicos estaban lejos de mostrar directamente una moral apta para los lectores medievales, puesto que no se delimitaba de forma clara la responsabilidad (el responsable) y el grado de verdad de lo que decían los personajes. Eso mismo justificó la existencia del comentario escolástico del dominico inglés Nicolás Trevet, que tendrá tanta fortuna en los territorios hispánicos. Por otra parte, los diálogos de Séneca y los flori$\operatorname{legios}^{5}$ dependientes de sus obras auténticas o atribuidas difundían sin demasiados problemas una parte -solo- del pensamiento del autor clásico, que además venía con la aureola de haber sido amigo de San Pablo y de poseer una filosofía cercana al cristianismo. Aunque lejos de ser verdad, estas y otras circunstancias facilitaban que se pudiera acceder a sus páginas sin excesivas prevenciones: con los dialogi, el lector tenía ante sus ojos, con observaciones o sin ellas, textos que vehiculaban filosofía moral senequista o que se presentaban como tales. Otra cosa muy diferente es si esta se ofrecía sistematizada o no. El ya clásico libro de Blüher ${ }^{6}$ sobre la presencia de Séneca en España nos enseña que no: llegó el Séneca moral, con el añadido frecuente de glosas marginales o de prólogos preventivos, y el Séneca sentencioso, presente en multitud de florilegios y excerpta ${ }^{7}$. En este contexto general y por orden del papa Clemente VI, pergeñó el dominico Luca Mannelli su Tabulatio et

M.-Ch. Bornes-Varol y M. a Sol Ortola) (2015), pp. 129-160. Para las versiones de las Epistolas, remito a Tomàs Martínez Romero, «Las versiones castellanas de la Epistolas de Séneca (BNE 8852)», en Revista de Filología Española, 94 (2014), pp. 175-208.

${ }^{5}$ Para los florilegios con fragmentos trágicos, remito a G. Brugnoli, «Le tragedie di Seneca nei Florilegi medioevali», en Studi Medievali, ser. 3:1 (1960), pp. 138-152; M. Pastore-Stocchi, «Un chapitre d'histoire littéraire aux XIV et $\mathrm{XV}^{\mathrm{e}}$ siècles: "Seneca poeta tragicus"》, en Les tragédies de Sénèque et le théâtre de la Renaissance, ed. de J. Jacquot, Paris, CNRS, 1964, pp. 11-36; B. Munk Olsen, «Les florilèges et les abrégès de Sénèque au Moyen Âge», en Giornale italiano di filologia, 52 (2000), pp. 163-183. Aún proporciona materiales interesantes sobre el Séneca medieval Enzo Franceschini, «Glosse e commenti medievali a Seneca tragico», en Studi e note di filologia medioevale, Milano, Vita e pensiero, 1938, pp. 1-105. El territorio castellano, evidentemente, tampoco está exento de florilegios: B. Arévalo Martín, «La presencia de las Epistulae ad Lucilium de Séneca en los florilegios conservados en España», en Baetica renascens, ed. de J. M. Maestre, J. G. Montes y R. J. Gallé, Málaga-Alcañiz, Federación Andaluza de Estudios Clásicos-Grupo Editorial 33-Instituto de Estudios Humanísticos, 2014, vol. 2, pp. 691-701.

${ }^{6}$ Karl Alfred Blüher, ob. cit.

${ }^{7}$ O ambos. En la traducción de los Proverbios de Séneca, Pero Díaz de Toledo no puede evitar dejar su huella en forma de «esplanaçión»: «Seneca puso aqui algunas sentençias breues \& conpendiosas a las quales por que mas se entiendan o mas verdaderamente fablando por que ayan causa de pensar los que mas querran porne alguna esplanaçion \& declaraçion a aquellas segund mi pobre juizio sentira» (citado por L. Godinas, «Los Proverbios de Séneca en la discusión en torno al humanismo castellano del siglo XV», en Literatura y conocimiento medieval. Actas de las VIII jornadas medievales, ed. de L. von der Walde et al., México D. F., UNAM-UAM-El Colegio de México, 2003, pp. 279-296, pp. 288-289). Los comentarios permiten que los Proverbios sean también una guía segura para el príncipe, que es al final el destinatario privilegiado de la versión. En el ánimo de Díaz de Toledo debería estar que su versión pudiese llegar -como de hecho lo hizo-a un doble destinatario, el más concreto del príncipe y el más abierto de los laicos deseosos de nuevas lecturas. Conscientemente, no entro aquí en la evaluación del nuevo público 
expositio Senecae, una especie de enciclopedia temática glosada de fragmentos del autor latino ${ }^{8}$. Bien es verdad que los transcritos por Mannelli podían leerse junto a un buen conjunto de comentarios.

Aunque no de forma regular ni siempre con un criterio definido, las selecciones y compendios medievales a menudo llegaron antes y en mayor número que el texto completo de las obras. Se trata de un fenómeno conocido, que se produce con asiduidad en los siglos XIV y XV. En el Cartagena traductor, resulta bastante evidente ${ }^{9}$. Cuando este decide traducir a Séneca a instancias de Juan II, allá por 1431, empieza por la Copilaçión de algunos dichos de Séneca, directamente vinculada a la Tabulatio de Mannelli. Coetáneo ${ }^{10}$ es el Título de la amistança o del amigo, que corresponde a las entradas Amicitia vel amicus y Amor de esta misma Tabulatio, junto con las glosas correspondientes, que casi pasan intactas al castellano ${ }^{11}$. Unos años antes, durante el reinado de Martí l'Humà (†1410), ya se había traducido al catalán el texto de Mannelli ${ }^{12}$, y no es sorprendente, pues se sabe que las traducciones a esta lengua son anteriores ${ }^{13}$. Otro mérito en el haber del dominico florentino fue la declaración del corpus (pseudo)senequista del que se valió para su trabajo ${ }^{14}$,

lector ni tampoco entraré en consideraciones sobre la posición de Cartagena frente a los studia humanitatis, que quedan fuera del objetivo de estas páginas.

${ }^{8}$ Sobre esta obra, T. Kaeppeli, OP, «Luca Mannelli (†1362) e la sua Tabulatio et Expositio Senecae», en Archivum Fratrum Praedicatorum, 18 (1948), pp. 237-264. Carla Maria Monti y Francesca Pasut («Episodi della fortuna di Seneca tragico nel Trecento. 1. Un'edizione tardo trecentesca delle tragedie di Seneca», en Aevum, 73:2 (1999), pp. 513-534, p. 514) incluyen la Tabulatio dentro de la corriente trecentista dedicada a la exégesis de las Tragedias.

${ }^{9}$ Luis Fernández Gallardo, «Tradición clásica, política y humanismo en la Castilla del Cuatrocientos. Las glosas de Alonso de Cartagena a De Providentia», en Anuario de Estudios Medievales, 24 (1994), pp. $967-1002$, p. 979.

${ }^{10}$ Hago mía la ordenación propuesta por Georgina Olivetto en Título de la amistança. Traducción de Alonso de Cartagena sobre la «Tabulatio et expositio Senecce» de Luca Mannelli, San Millán de la Cogolla, Cilengua, 2011, pp. 63-64, 69. Para el De vita beata, véase de la misma autora, «Observaciones preliminares para una edición crítica del Libro de la vida bienaventurada», en Literatura medieval y renacentista en España: líneas y pautas, ed. de N. Fernández Rodríguez y M. Fernández Ferreiro, Salamanca, SEMYR, 2012, pp. 783-790. Olivetto propone para el Título otra posible fecha, después de 1440, aunque parece más lógico, desde un punto de vista estrictamente conceptual y dentro del conjunto de su obra, que su redacción fuese de las primeras de la etapa senequista.

${ }^{11}$ G. Olivetto, Título, ed. cit., p. 128.

${ }^{12}$ Tomàs Martínez Romero, «Algunas consideraciones sobre la Tabulatio Senecae y su traducción catalana», en Euphrosyne, 29 (2001), pp. 95-110. Solo conservamos la primera parte y no sabemos hasta qué punto se tradujo la segunda.

${ }^{13}$ Remito a Tomàs Martínez Romero, Un clàssic, ob. cit. Una actualización del mismo autor, en «Seneca catalanicus o la recepció medieval d'un autor llatí», en Auriga, 81 (abril 2016), pp. 4-8.

${ }^{14}$ En la traducción catalana que tengo a disposición, es el que sigue: «sobre les Epístoles de Séneca mateix a sent Pau, sobre .xxii. libres de les Epístoles a Lucillo, sobre 1 libre De vida benauyrada, sobre dos libres De la Providència de Déu, sobre .iii. libres De ira, sobre .vii. libres De benefficis, sobre .vi. libres De qüestions naturals, sobre .iv. libres De declinacions, sobre .ii. es [sic] libres De clemència, sobre· 1 libre De tranquilitat de coratge, sobre 1 libre De breu vida, sobre 1 libre De consolació a Màrcia, sobre 1 libre De 
compuesto por obras de diverso calibre: las Epístolas a Lucilio y a San Pablo, los Diálogos y las Consolaciones, las Tragedias, el De moribus o la Formula vitae honesta de Martín de Braga. Probablemente fue también el repertorio que llegó a conocimiento de Cartagena ${ }^{15}$ y es, de hecho, el que tradujo en gran parte. No fue el único que lo dio por bueno. Como demostró Georgina Olivetto $^{16}$, Mena lo reprodujo en el conocido comentario a la estanza 37 de la La coronación del marqués de Santillana.

La ausencia de las Tragedias en la lista de traducciones de Cartagena no se puede justificar, pues, por desconocimiento de su existencia. Sin embargo, y aparte de prevenciones morales, se me ocurre aún otro argumento mucho más práctico y elemental para explicar por qué no las versionó: por aquellos años, con toda seguridad ya corría por Castilla una traducción al castellano. Sabemos que el Marqués de Santillana patrocinó una ${ }^{17}$. Nos lo cuenta en la conocida carta a su hijo Pedro González de Mendoza, a la sazón estudiante en Salamanca, donde afirma que mandó traducir «a ruego e instançia» suya algunas obras clásicas:

A ruego e instançia mía, primero que de otro alguno, se han vulgarizado en este reyno algunos poetas, assí como la Eneida de Virgilio, el Libro mayor de las transformaçiones de Ovidio, las Tragedias de Lucio Anio Séneca e muchas otras cosas en que yo me he deleytado fasta este tiempo e me deleyto y son assí como un singular reposo a las vexaçiones y travajos que el mundo continuamente trae, mayormente en estos nuestros reynos ${ }^{18}$

consolació a Políbio, sobre 1 libre De consolació a Hèlbia, sobre 1 libre De custumes, sobre 1 libre De .iiii. virtuts, qui en altra guisa és dit e·ntitulat De còpia de paraules, sobre·l libre De estudis liberals, sobre·1 libre De remeys de fortuna, sobre les .x. Tragèdies e sobre 1 Libre de joc de Clàudio; mas del Libre de proverbis e de pobrea, no n'he res de tot en tot pres, car aquests dos libres són trets dels dits seus paraula a paraula, axí com appar al diligentment esguardan. Mas del libre Contra supersticions, lo qual sent Agustí moltes vegades al·lega e majorment en lo .vi. de la Ciutat de Déu, no n'he res pres, car no l'he pogut haver» (Biblioteca de la Universitat de Barcelona, ms. 282, f. 2r).

${ }^{15}$ Tal y como se apunta en G. Olivetto, Título, ed. cit., p. 41: «el corpus llegado a manos del traductor no fue en su esencia diferente del consultado por Luca Mannelli».

${ }^{16}$ Georgina Olivetto, «Juan de Mena, ¿lector de Séneca?», en Estudios sobre la Edad Media, el Renacimiento y la temprana modernidad, ed. de Francisco Bautista Pérez y Jimena Gamba Corradine, San Millán de la Cogolla, SEMYR-Cilengua, 2010, pp. 321-329, pp. 325-326.

${ }^{17} \mathrm{Y}$ puede que no sea ocioso recordar la relación estrecha entre este y Cartagena, puesta de manifiesto en la conocida Qüestión dirigida por el marqués al sabio erudito, $c f r$. Ángel Gómez Moreno, «La Qüestión del Marqués de Santillana a don Alfonso de Cartagena», en El Crotalón. Anuario de Filología Española, 2 (1985), pp. 335-363.

${ }^{18}$ Íñigo López de Mendoza, Marqués de Santillana, Obras completas, ed. de Ángel Gómez Moreno y Maximilian P.A. M. Kerkhof, Barcelona, Planeta, 1988, pp. 456-457. 
A menudo se ha inferido directamente que a Santillana se debe la primera versión de las Tragedias, cuando en su declaración se refiere a la primacía en el patronazgo, no necesariamente en la traducción. Sea como sea, en la actualidad conocemos solo dos romanceamientos castellanos, dependientes ambos del catalán (de finales del XIV), que les sirve de modelo ${ }^{19}$. Siguiendo a Round, cabe deducir que o bien la traducción de Santillana se perdió o es una de estas $\operatorname{dos}^{20}$. Además, como la catalana se aprovechaba en mayor o menor medida del comentario de Trevet $^{21}$, la influencia de este llegaba también, por vía indirecta, a la versión castellana. Nos interesa sobre todo el prólogo latino, donde el erudito inglés definía el género tragedia y los tres modos de narración:

tragedi sunt qui antiqua gesta atque facinora sceleratorum regum luctuoso carmine, spectante populo, concinebant. [...] Scripserunt autem poete triplici caractere, quia vel modo narrativo, in quo solus poeta loquitur ut in Georgicis, vel dragmatico, ubi nusquam poeta loquitur sed tantum persone introducte, et iste modus convenit proprie tragedis et comedis; tercius modus mixtus ex duobus est, ubi et quandoque poeta loquitur et quandoque persone introducte, sicut Virgilius in Eneidos, cuius materia licet sit tragica tamen liber ipse more tragico non scribitur propter hoc quod poeta ibi aliquando loquitur cum personis introductis. Virgilius ergo in Eneydos, Lucanus et Ovidius de transformatis poete tragici dici possunt quia de materia tragica, scilicet de casu regum et magnorum virorum et de rebus publicis scripserunt, sed tamen minus proprie. Seneca autem in libro, qui pre manibus habetur, non solum de materia tragica sed etiam scripsit more tragico; et ideo merito liber iste liber tragediarum dicitur; continet enim luctuosa carmina de casibus magnorum in quibus nusquam poeta loquitur sed tantum persone introducte ${ }^{22}$

La definición proviene directamente de San Isidoro (Etym. XVIII, 45), como también la triple división (Etym. VIII, 7) ${ }^{23}$. Trevet, hablando de los modos de narración, dejaba por sentado que tanto en las tragedias como en las comedias no intervenían los poetas, sino persone introducte, con lo cual

${ }^{19}$ T. Martínez Romero, «The Reception», art. cit., p. 107.

${ }^{20}$ N. G. Round, «Las traducciones medievales», art. cit., p. 191.

${ }^{21}$ Véase Tomàs Martínez Romero, «Notes sobre la difusió de les obres de Nicolau Trevet a Catalunya: la traducció de les Tragèdies de Sèneca i els comentaris de Trevet», en Caplletra. Revista Internacional de Filologia, 13 (1992), pp. 117-134; y L. A. Sèneca, Tragèdies. Traducció catalana medieval amb comentaris del segle XIV de Nicolau Trevet, ed. de Tomàs Martínez Romero, Barcelona, Barcino, 1995, 2 vols.

${ }^{22}$ E. Franceschini, «Glosse e commenti», art. cit., p. 35.

${ }^{23}$ «Apud poetas autem tres characteres esse dicendi: unum, in quo tantum poeta loquitur, ut est in libris Vergilii Georgicorum; alium dramaticum, in quo nusquam poeta loquitur, ut est in comoediis et tragoediis; tertium mixtum, ut est in Aeneide. Nam poeta illic et introductae personae loquuntur» (Isidori Hispalensis episcopi Etymologiarum sive originum libri XX, ed. de W. M. Lindsay, Oxford, Clarendon Press, 1911). 
Séneca y su pensamiento quedaban en un segundo lugar o, cuanto menos, en un plano confuso. El comentario tenía que aclarar, pues, cómo se debía entender la materia tragica y en qué momento el parlamento de un personaje vehiculaba pensamiento de Séneca, además de incluir las críticas o censuras a los pasos en que el filósofo se distanciaba de la doctrina cristiana.

Sin embargo, las traducciones catalana y castellana solo recogían aquello que estrictamente correspondía a la descripción isidoriana de tragedia: «Síguense los prólogos o prohemios de las Tragedias de Séneca. Et son dichas tragedias porque contienen dictados llorosos de crueldades de reyes et grandes prínçipes». La omisión, si no se debía a la falta del texto en su modelo, podía tener algunas consecuencias. No obstante, aunque Cartagena desconociese el texto completo del comentario o, incluso, no supiese de la versión castellana de las Tragedias -supuesto improbable-, sí que podemos presumir que tenía a su alcance las Etimologías y, por tanto, los fragmentos correspondientes a la definición de tragedia y a los modos de narración. De hecho, la explicación reaparecía nuevamente en la voz auctor de aquella Tabulatio en que se basó para redactar la Copilaçión:

Tragoedi dicti, quod initio canentibus praemium erat hircus, quem Graeci TRAGOS vocant. Vnde et Horatius (A. P. 220): Carmine qui tragico vilem certavit ob hircum. Iam dehinc sequentes tragici multum honorem adepti sunt, excellentes in argumentis fabularum ad veritatis imaginem fictis. Comoedi appellati sive a loco, quia circum pagos agebant, quos Graeci KOMAS vocant, sive a comisatione. Solebant enim post cibum homines ad eos audiendos venire. Sed comici privatorum hominum praedicant acta; tragici vero res publicas et regum historias. Item tragicorum argumenta ex rebus luctuosis sunt: comicorum ex rebus laetis

He expresado ciertas dudas sobre la posibilidad de que Cartagena hubiese conocido el texto latino completo de Trevet. Y hay motivos para ello. En el prólogo a Hercules furens, después de exponer el argumento general de la tragedia, se le aplican las cuatro causas aristotélicas: causa efficiens: Séneca; causa materialis: la furia de Hércules; causa formalis: el modo dramático; causa finalis: la delectación de los oyentes. A partir de esta última, de la causa finalis, se puede suponer que existe una lectura ética adjudicable a la tragedia, según Trevet: «in quantum hoc narrantur quedam laude digna, quedam vituperio, potest aliquo modo liber hic supponi ethice, et tunc finis eius est correctio morum per exempla hic posita ${ }^{24}$. En este punto el exegeta

${ }^{24}$ Nicolai Treveti Expositio Hercules furentis, ed. de V. Ussani, Roma, Edizioni dell'Ateneo, 1959, pp. 4-5. Véase también A. Kelly, Ideas and forms of tragedy from Aristotle to the Middle Ages, Cambridge, 
inglés da por acabado el proemio y comienza en seguida la ordinatio $^{25} . \mathrm{Cu}-$ riosamente, tanto las causas como la interpretación ética estaban ausentes en las traducciones peninsulares. Cabe inferir, por tanto, que Cartagena o no quiso rentabilizar la vena ética, dando por cerrado así cualquier margen de beneficio a las tragedias, o no tenía al menos este fragmento trevetiano. Las dos posibilidades son creíbles y factibles. De hecho, como se verá, Cartagena parte de una visión negativa del género.

No era, sin embargo, la única definición que corría por Castilla. El Marqués de Santillana, que se refería a Séneca en tanto que escritor moral en su Defunsión de Don Enrrique de Villena, en la carta a Violante de Prades que servía de prólogo a la Comedieta de Ponza (c. 1443) sostenía que «Tragedia es aquella que contiene en sí caýdas de grandes reyes e príncipes, así como de Ércoles, Príamo e Agamenón e otros tales, cuyos nasçimientos e vidas alegremente se començaron e grande tienpo se continuaron e después tristemente cayeron ${ }^{26}$. Estas líneas se incluían en un fragmento dedicado a distinguir entre tragedia, sátira y comedia, remisible muy posiblemente a los comentaristas de Dante ${ }^{27}$. El Marqués mantenía la altura social de los personajes trágicos, pero, a diferencia de Isidoro-Trevet, en lugar de sus crueldades y gestas importaba su progresión desde la alegría a la tristeza. No andaba muy lejos de esta visión la Expositio de Trevet a la Consolatio de Boecio, cuando afirmaba: «tragedia est carmen de magnis criminibus vel iniquitatibus a prosperitate incipiens et in adversitatem terminans. Et dicitur tragedia a tragos, quod est hircus, et $o d a$, cantus $\rangle^{28}$. Si bien la etimología y la consideración de la tragedia como un carmen podían acercarlo a Isidoro, el paso de la prosperidad a la adversidad estaba influido por una tradición que podía remitir a Guillermo de Conches y que también seguían artes poéticas como las de Vinsauf o Juan de Garlandia ${ }^{29}$.

Cambridge University Press, 1993, p. 132.

${ }^{25}$ En esta parte, por cierto, podemos leer un interesante comentario sobre la recitación de tragedias y comedias en el teatro: «nota quod tragedie et comedie solebant in theatro hoc modo recitari; theatrum erat area semicircularis, in cuius medio erat parva domuncula, que scena dicebatur, in qua erat pulpitum super quod poeta carmina pronuntiabat; extra vero erant mimi, qui carminum pronunciationem gestu corporis effigiabant per adaptationem ad quemlibet ex cuius persona loquebatur» (ibídem).

${ }^{26}$ Íñigo López de Mendoza, ed. cit., p. 436.

${ }^{27}$ Según sus editores (ibídem, p. LXVIII). La definición de tragedia de Santillana en la Comedieta no la extrajo, pues, de la traducción de las Tragedias y, por tanto, no puede servir como argumento de datación, como quería Round, «Las traducciones medievales», art. cit., pp. 190-193.

${ }^{28}$ Citado por A. Kelly, ob. cit., p. 127.

${ }^{29}$ Ibid., pp. 78; 99-101. Geoffrey de Vinsauf: «Tragedia carmen est in quo agitur de contemptu Fortune, ostendens infortunia gravium personarum, et incipit a gaudio et finit in luctu» (ibidem, p. 99); Juan de Garlandia: «Tragedia est carmen gravi stilo compositum, incipiens a gaudio et terminans in luctum» (ibídem, p. 101). 
Todos estos ingredientes se podían leer incluso sin salir del territorio senequista. Carla Maria Monti y Francesca Pasut ${ }^{30}$ han recuperado un interesantísimo testimonio del siglo XIV del Séneca trágico que incluye un accessus con la explicación del título tragedia, su etimología y sus características. Los argumentos-resúmenes de cada una de las tragedias son deudores del comentario trevetiano, excepto los de Thyestes y Hercules furens. Interesa parte del texto de este último, que remite a las Derivationes de Huguccio de Pisa $^{31}$-en las cuales, por cierto, se muestra un interés real por aquello que hoy denominaríamos «representación»:

Sic etiam contigit de qualibet tragedia: incipit a rebus pulcris et finit in turpem, incipit a letitia et desinit in mestum. Unde dicit Ugutio quod, volentes indicare amico prosperum principium et finem letum, optamus tragicum principium et comicum finem. Nam comedia finit in leta ubi contrarium explicat tragedia. Notandum tamen quod quodlibet opus mere heroicum generaliter tragicum appellatur ab alta materia, unde Oratius: carmine qui tragico vilem certavit ob hyrcum. Sed per excellentiam opus istud vocatur Tragedie. Nam precipue infortunati describuntur eventus et magnarum rerum et sublimium personarum $^{32}$

Si continuamos realizando un recorrido somero por textos castellanos, encontramos en la Coronación (1438) de Mena algunos de los elementos que han ido apareciendo anteriormente:

Tragedia es dicha la escritura que fabla de altos fechos, e por bravo e sobervio e alto estilo, la qual manera siguieron Omero, Vergilio, Lucano, Estaçio; por la tragedia escritura, puesto que comiença en altos prinçipios, su manera es acabar en tristes e desastrados fines ${ }^{33}$

El fragmento, según su editor, puede remitir a Benvenuto da Imola, que se basa en una definición de tragedia caracterizada por su alto estilo y por su final triste. Sea así o no, lo cierto es que el «alto estilo» de Mena podía mantener aún alguna relación lejana con el more tragico de Isidoro, aquel que acompañaba a la materia tragica, mientras que la definición de tragedia

\footnotetext{
${ }^{30}$ C. M. Monti y F. Pasut, art. cit., p. 524.

${ }^{31}$ Ya lo indican convenientemente las editoras (ibidem, p. 529): «comedia a tristibus incipit, sed cum letis desinit, tragedia e contrario; unde in salutationi solemus mittere et optare amicis tragicum principium et comicum finem, id est bonum et letum principium et bonum et letum finem» (Deriv., s. v. oda).

32 Ibídem, p. 526.

${ }^{33}$ Juan de Mena, Obras completas, ed. de M. A. Pérez Priego, Barcelona, Planeta, 1989, p. 107.
} 
como un scriptum ${ }^{34}$, y no como un carmen, seguía la senda de Conches. Con respecto a Santillana, Mena privilegiaba los «altos fechos» en detrimento de los protagonistas de tales «fechos», que interesaban más al Marqués. En cierto modo, estas y otras definiciones remitían a una tradición crítica a veces difícil de individualizar.

Cartagena, claro está, conocía la existencia de las Tragedias, por su formación, por su lectura de la obra de Mannelli y por las referencias a estas que se incluyen en el texto y en las glosas de la Copilaçión y del Título de la amistança ${ }^{35}$. Si no las tradujo fue, no por desconocimiento, ni por carecer de un texto base latino ${ }^{36}$, sino probablemente por cuestiones más profundas, relacionadas tanto con el tipo de destinatario, como con las finalidades a las que obedecía según él el uso de la obra de Séneca, que ya había sustanciado en el celebérrimo prólogo al Libro primero de la Providencia de Dios, frecuentemente citado:

E por cuanto en algunos lugares estaba oscuro por tañer historias antiguas que no son conocidas, señalelo en los márgenes contando brevemente cuanto bastaba a la declaración de la letra. E así mismo donde sentí, perdóneme Séneca, alguna conclusión que contradijiese a los santos doctores, contradíjela luego, porque no le dejemos con ella pasar e el que lo oyese no fuese engañado. $\mathrm{Ca}$ en tanto es de dar favor a escrituras de los gentiles, en cuanto de la católica verdad no desvían ${ }^{37}$

Si la mayor parte de las notas marginales se sometían a hábitos de la lectio, en otras partes había de imponer directamente un correctivo, una censura. Alfonso de Cartagena declaraba abiertamente su actitud dialéctica y a la vez dialógica con respecto al texto de Séneca a fin de acomodarlo a los lectores de la versión, lógicamente cristianos y ávidos de aprovechar su trabajo de

${ }^{34}$ A. Kelly, ob. cit., p. 78: «Conches's definition of tragedy as a scriptum beginning in prosperity and ending in adversity, which answers to nothing in Isidore or other available traditions, was to have an important future, along with its comedic converse. His characterization establishes the form as a purely narrative genre».

${ }^{35}$ J. Fernández López y E. del Río («Las Tragedias de Séneca en la Copilación de Alonso de Cartagena», en Manipulus studiorum. En recuerdo de la profesora Ana María Aldama Roy, ed. de M. T. Callejas et al., Madrid, Escolar y Mayo, 2014, pp. 375-394) transcriben los quince fragmentos de las Tragedias incluidos en la Copilaçión, los cuales, según ellos, se centran en «el ejercicio del poder por parte del príncipe y lo que podríamos llamar la "condición femenina"».

${ }^{36}$ Otra cosa sería la calidad y la completez de ese texto. Por aquellos mismos años en que Cartagena traducía a Séneca, se encuentran diversos manuscritos de las tragedias latinas en la biblioteca papal de Benedicto XIII con las pertinentes glosas de Nicolás Trevet.

${ }^{37}$ Alfonso de Cartagena, Los Cinco libros de Séneca, ed. de J. L. Villacañas, Murcia, Tres Fronteras, 2012, ob. cit., p. 205. 
traducción con comento ${ }^{38}$. Al fin y al cabo, en eso consistía su cometido y el de los profesionales formados para ello. Cartagena encuentra en los márgenes un lugar para volcar sus juicios doctrinales -la mayor parte anteriores a la traducción- $\mathrm{y}$ al mismo tiempo para ejercer a posteriori un control sobre sus potenciales receptores, algunos demasiado devotos de la tradición clásica ${ }^{39}$.

Nuestro autor muestra una clara prevención frente al Séneca no moral y claramente frente al trágico. Las razones que da tienen que ver con el fingimiento de los protagonistas y de las acciones de las tragedias. Es más, se duele de que alguien pueda perder el tiempo con tales pasatiempos. En el tratado De las artes liberales habla del nulo provecho de esas páginas, con personajes y dioses inexistentes, y denuncia de paso lo absurdo de divagar sobre cuestiones concretas relacionadas con el mundo clásico:

No debemos trabajar por saber si fue Homero antes que Isidoro, ca no cumple más saber esto que si quisiésemos saber si era mayor Hécuba que Elena y por qué acabó tan mal su edad. E piensas tú que nos provecha algo andar preguntando por saber los años de Patroculo y de Arquiles, o por saber dónde erró Ulises el camino. Mejor era trabajar porque nos nunca erremos, no tenemos vagar de oír si echó la tormenta a Ulises en Italia o en Sicilia o en otra parte del mundo que no supimos [...] Para qué trabajas por saber si Penélope fue casta o no, o si dio buen ejemplo o malo en su siglo. $O$ si en veyendo a Ulises sospechó que era él ante que lo supiese. Déjate desto y enséñame qué cosa es castidad, e cuánto bien hay en ella así para el cuerpo como para el ánima ${ }^{40}$

${ }^{38}$ Nicholas G. Round - «"Perdóneme Séneca”. The Translational Practices of Alonso de Cartagena», en $B H S, 75$ (1998), pp. 17-29- estudia las diversas prácticas traductológicas que Cartagena emplea de acuerdo con el destinatario, la fecha y la funcionalidad del texto, creando incluso dobles traducciones. Sobre la actitud de Cartagena hacia los clásicos, léase también la reciente contribución de T. González Rolán, A. López Fonseca y J. M. Ruiz Vila, La génesis del humanismo cívico en Castilla: Alfonso de Cartagena (1385-1456). Edición y estudio de textos seleccionados sobre el saber, la diplomacia y los estudios literarios, Madrid, Escolar y Mayo, 2018.

${ }^{39}$ Véanse los inteligentes comentarios de Round, ibídem, p. 29, y de Luis Fernández Gallardo, «Alonso de Cartagena y el humanismo», en La Corónica, 37:1 (2008), pp. 1-41, p. 13.

${ }^{40}$ Los Cinco libros, ed. cit., p. 153. Las obras que no se incluyen en esta edición se citan según los siguientes testimonios manuscritos: BNE 6962: I y II De clemencia, Declamaciones, Breve copilaçion; BNE 9180: Remedios contra fortuna; BNE 8830: Libro de las quatro virtudes (=Formula honestae vitae, de Martín de Braga). El Título de la amistança se cita por la edición de G. Olivetto, Título, ed. cit. 
La utilidad moral, así, era inexistente ${ }^{41}$. Solamente se podía sacar rendimiento a esas lecturas si se leían no en sentido literal, sino en el figural ${ }^{42}$, aplicando pues los métodos ya conocidos por la exégesis bíblica. En una de las glosas a «Yo así lo creo» del Segundo libro de Séneca de la providencia de Dios, y a propósito de una intervención de Hipólito en la cuarta tragedia -Cartagena declara haberlo encontrado En el tratado de la caza, esto es, en el apartado correspondiente de la Tabulatio- se dice:

Aquí fINGE Séneca que habla Ypólito commo montero, loando el correr del monte. E commo ya en otro lugar dixe, LAS TRAGEDIAS NO HAN AUCTORIDAD DE DOCTRINA, POR QUANTO SÉNECA HABLA EN ELLAS SO NONBRE DE OTROS, los quales a las vezes exçeden en tenplamiento de la razón. Por ende, para aver alguna breve [buena $B$ ] enseñança para en lo que a la caça atañe, es a saber que la caça de muchas maneras se entiende en la escriptura, ca los tiranos e los apremiadores de la gente a las vezes son llamados caçadores porque apremian e caçan los onbres, e eso mesmo los lisonjeros, porque con palabras engañosas caçan los coraçones; e los que por dinero salen a matar el otro [sic; toro $A B D E F]^{43}$ o otra bestia fiera ${ }^{44}$

${ }^{41}$ Cartagena no pierde nunca de vista la Escritura. De las «fablillas» de los clásicos «devemos tomar e tomemos lo bueno e conforme a la ley de Dios», como dice un conocido fragmento del Título de la amistança: «E por ende los cathólicos, dexado lo malo que estos e los otros philósofos dizen, devemos tomar e tomemos lo bueno e conforme a la ley de Dios, es a saber, aquello que muy notablemente ellos fablan e tractan de las virtudes e buenas costunbres e de los otros saberes, en quanto non contrarían a la ley de Dios e a nuestra sancta fe cathólica» (Título de la amistança, ed. cit., p. 221).

${ }^{42}$ De hecho, como reconoce Cartagena, Séneca ya había interpretado en más de una ocasión las historias mitológicas: «Las fablillas fingen que Júpiter, prínçipe de los dioses, quando quiere enviar rayos tiene consejo con los otros dioses, etc. E de aquesta fablilla arguye Séneca que los juezes non deven pronunçiar sentençias de muerte sin aver primeramente consejo con los sabios» (ibídem, p. 243).

${ }^{43}$ Doy fe de las divergencias entre testimonios para insistir en la necesidad de una edición crítica integral de las obras de Cartagena. En esta ocasión, las letras identifican los siguientes manuscritos: A (BNE 817; Familia $\varepsilon$, base de la edición de 1491); B (BNE 1615. Familia $\varepsilon \varepsilon$ ); C (BNE 5568. Familia $\beta$ ); D (BNE 6765. Familia $\alpha$ ); E (BEN 6962. Familia $\gamma$ ); F (BNE 8188. Familia $\delta$ ); ed. (Cinco libros de Séneca, Sevilla, Ungut-Polono, 1491. Ejemplar de la BNE: Inc. 2564). Para la asignación de familias, sigo la propuesta de Round, «Alonso de Cartagena», art. cit., pp. 123-147.

${ }^{44}$ A partir de ahora cito por la edición de 1491 e indico la correspondencia con Los Cinco libros, ed. cit., en este caso pp. 278-279. A este fragmento, sigue otro también interesante: «E estas tres maneras de caças son en qualquier onbre vedadas; e de qualquier destas, segund algunos doctores quieren, se puede entender lo que dize santo Augustín e ponen los canonistas en la LXXVI [LXXXVI $A D$, ochenta e seys $B]$ distinçión, que no se halla que caçador alguno fuese sancto [...] Mas segund dize Aristótiles en el VI de las Éthicas, es acto de onbre muelle e desordenada disoluçión, ca el que continua la caça paresçe que quiere todavía holgar e no es para sofrir los trabajos de la governaçión de la república. E por esto, reprehenden mucho las historias al rey de León, don Favila, hijo del rey don Pelayo, e le juzgan por onbre liviano, porque seguía mucho el correr del monte; e tanto lo siguió, hasta que lo mató un oso. Pero yr a caça algunas vezes por recreaçión del cuerpo quando están fatigados, commo [cosa $D E$ ] es pertenesçiente a los reyes e prínçipes e a los otros señores, e correr monte en su tienpo e sazón, porque es juego que no solamente recrea, mas aun exerçita las fuerças del cuerpo e el uso del cavalgar, e demuestra algund tanto el denuedo, las quales son cosas que pertenesçen al estado de la cavallería. Pero en tanto que la haga en 
Del «fingimiento»-concepto nuclear- que contienen estas historias, Cartagena saca fruto en forma de interpretación tropológica. También es muy visible el sentido no literal en este paso del Título de la amistança:

E comoquier que Valerio [Dicta IV, vii, 4] non aprueva esta fablilla [del descenso de Teseo al infierno para seguir a su amigo Periteo], contando por cosa FINGIDA, por ser inposible de natura de aver acaesçido verdaderamente tal cosa, e denuesta e maltrahe la gente de los griegos, porque dize que usan destos enxenplos ENFINGIDOS, e loa la gente romana, porque dize que usa de enxenplos verdaderos, pero aun con todo esto salvar se puede el enxenplo de los griegos. Ca dezir ellos que el omne costreñido por la gran amistad que ha con su amigo deçiende por él a los infiernos, dévese tomar FiguralmENTE e non a la letra [...]. E por ende, dixieron bien los griegos que por el amor o amistad descendían los omes a los infiernos por sus amigos, que es tanto como si dixieran que por su amor o amistad se ponen a peligro de muerte e a otras desaventuras o trabajos que son egualados a la muerte, la qual en muchos lugares de la Sancta Escriptura se toma por el infierno ${ }^{45}$

En contra de lo que opina Valerio Máximo, el enxenplo de los griegos se puede salvar si se interpreta la bajada a los infiernos en la dirección conveniente y se identifica esta con el "peligro de muerte e otras desaventuras o trabajos que son egualados a la muerte». La lectura figural obviaba los enxenplos enfingidos, un obstáculo que Valerio, claro está, no podía haber superado precisamente porque no tenía los instrumentos para hacerlo en el sentido que quería Cartagena. Siguiendo la esfera de san Basilio y tantos otros, este asumirá como válida la apropiación de las doctrinas basadas en la razón natural en beneficio propio, como confirmará en la «Introducción»a De la vida bienaventurada ${ }^{46}$.

No son extrañas semejantes interpretaciones entre los escritores del xv, Mena incluido, quien reconoce por debajo de la literalidad de las historias

tienpos convenientes e guardando los solennes ayunos e fiestes [sic] e que lo tomen por solaz e por juego, e que no cuyden que hazen mucho sy son en ello muy exçelentes, ca hazer dello grand mençión e despender tienpo demasiado, commo algunos ovo e ay, que gastan el día en la caça e la noche en hablar lo que allá acaeçió, no es loable en persona alguna por grande que sea; mas avida razonable recreaçión, deven tornar luego a hazer las cosas que a su cargo esperan».

${ }^{45}$ G. Olivetto, Título, ed. cit., p. 203.

46 «aunque los filósofos no lo entendieron tan alto como después fue a los católicos revelado, pero siguiendo la razón que tenían, dieron algunas buenas doctrinas que a esto no poco aprovechan si son bien y a buen fin entendidas». Léase también la «Introducción» de Villacañas a Los Cinco libros, ed. cit. Lógicamente, estos hechos se relacionan con la desconfianza general y previa contra los clásicos (véase, por ejemplo, Interpretation and allegory: antiquity to the modern period, ed. de J. Whitman, Leiden, Brill, 2000). 
mitológicas otra lectura posible: «Por Jasón podemos entender qualquiera que anda por la semejante manera engañando el mundo con el ardor de la luxuria dando fee a muchas e non la teniendo con ninguna» ${ }^{47}$. Del mismo modo, Enrique de Villena, en sus Doce trabajos de Hércules, dirá a partir de Hercules Oetaeus vv. 1989-1996:

Otros entienden que esto [los doce trabajos] espiritualmente entender se deve tomando por Ércules Dios, que es domador de todos viçios e de todas bestiales costunbres. Asi paresçe que lo diga Séneca en la fin de la su postrimera tragedia, invocando a Dios que cate a los omnes del mundo e tuelga los viçios, llamándolo en aquel lugar domador de las fieras e allegándole los erculinos trabajos ${ }^{48}$

Poco importa para los objetivos que se pretenden si este $\mathrm{u}$ otro pasaje remite o no a la Istoria fiorita de Guido da Pisa, fuente de Villena ${ }^{49}$. Era la razón y la doctrina lo que había de velar por la recta interpretación de los autores antiguos y, más aún, si trataban de cosas fingidas, con las que se solía vincular la poesia. En el Segundo libro de Séneca de la providencia de Dios ${ }^{50}$, Cartagena comenta el texto de una intervención de Egisto en la octava tragedia (Agam. vv. 284-287): «Nunca entra lealtad por el umbral de la puerta del rey». Evidentemente, podía interpretarse mal si se aplicaba directamente a la realidad inmediata, por eso necesitaba la pertinente glosa:

No es de entender así generalmente que no entra lealdad en las casas reales, ca esto falso sería, pues ovo muchos en los tienpos antiguos que reçibieron muertes por sus reyes e señores en diversas partes del mundo, e en esta España en que bivimos, lo qual quien historias lee no puede negar. E no ay dubda que ay oy en día muchos que reçibirían muerte o peligro por guardar su lealdad si acaso viniese. Por ende, es de considerar que este dicho de Séneca es de LAS TRAGEDIAS, ONDE NO HABLA DANDO DOCTRINAS GENERALES, MAS ESCRIVIÓ HABLANDO EN NOMBRE DE OTRO, DECLINANDO A LA UNA PARTE E A LAS VEZES A LA OTRA CONTRARIA, SEGUND QUE LA MATERIA LO PEDÍA. Por ende, los tales dichos no son razón de tomar por doctrina, sino en quanto concuerdan con la razón. E demás desto es de saber que aquí no habla generalmente de toda la lealdad, mas solo en quanto atañe a guardar el secreto ${ }^{51}$

47 Juan de Mena, ed. cit., p. 125.

${ }^{48}$ Enrique de Villena, Los doze trabajos de Hércules, ed. de M. Morreale, Madrid, Real Academia Española, 1958, p. 133 (con leves cambios en la puntuación).

49 Pedro Cátedra y Paolo Cherchi, «Introducción» a Los doze trabajos de Hércules (Zamora, por Antón de Centenera, 1483), Santander, Publicaciones de la Universidad de Cantabria, 2007, pp. 115-131.

${ }^{50}$ Téngase en cuenta que el contenido de este Libro segundo de la Providencia corresponde en realidad, aquí y en la edición de 1491, al texto de la Copilaçión. En otros testimonios, corresponde a la versión del De constantia sapientis.

${ }^{51}$ Los Cinco libros, ed. cit., p. 258. 
La «naturalización ${ }^{52}$ de los textos a la realidad que se vivía era una de las marcas más visibles del trabajo de Cartagena, obsesionado por ofrecer al rey un texto provechoso y en lo posible pragmático ${ }^{53}$.

Sin embargo, más que la interpretación, me interesa resaltar del fragmento la referencia a la falta de identidad entre actor y personaje, puesto que aparece en otro lugar con los mismos términos. En el Libro primero de la Providencia de Dios, traducido «por mandado» de Juan II, se leen las siguientes líneas sobre Faetón:

es de maravillar por qué Séneca, hablando en materia tan noble, quiso traher FICTIÓN DE POETA. Mas es de saber que no lo traxo él commo historia verdadera, ca çierto es que es fictión. E más sola mente la trahe por concluyr que por lo alto va la virtud. E algunas vezes en escripturas solennes e aun sanctas se allegan DICHOS DE POETAS, NO PORQUE EN SY SEAN VERDADEROS SYN VERDAD NI AYAN AUCTORIDAD, mas porque dellos se traya alguna cosa a propósito, segund que lo dize e prosygue Sant Gerónimo en la epístola que escrivió al grand orador. E en otras $[s i c]$ muchas [sic] lugares Séneca FINGE ALGUNAS FÁBULAS que, aunque no son verdaderas, pero atráhelas a propósito de lo que quiere dezir, asy commo en la tragedia primera lo dize sobre la parte «Asy lo creo». E asy lo dize commo Ypólito montero loando el correr del monte. E commo en otro lugar dixe, LAS TRAGEDIAS NO HAN AUCTORIDAD DE DOCTRINA POR QUANTO SÉNECA HABLA EN ELLAS SO NONBRE DE OTROS, los quales a las vezes exçende $[\mathrm{sic}]$ en tenplamiento de la razón. Por ende para aver alguna breve enseñança para en lo que caça atañe, es a saber que la caça de muchas

\footnotetext{
${ }^{52}$ Incluida la cristianización, claro está. En este mismo libro, por ejemplo: «Lo qual dice en la tragedia cuarta, fingiendo que ciertos hombres ayuntados en uno a que llama coro, como se ayuntan los clérigos en la iglesia, lloraban la muerte de Hipólito por los metros y versos siguientes, como a manera de himno: "oh cuántas ocasiones hacen los hechos humanales"》 (Los Cinco libros, ed. cit., p. 238). Sobre la tensión entre su formación de letrado y sus deberes como clérigo, véase L. Fernández Gallardo, «Tradición clásica», art. cit.

${ }^{53}$ Ese fenómeno se aplica incluso a la literatura en esta referencia probable a la Ilias latina: «La historia que habla de los hechos de Ulises llaman en griego Odisea y toda la historia de Troya llamaban los griegos Ilíada, porque a tierra de Troya decían Ylión; y Homero compuso aquellas historias, y no es este libro el de la conquista de Troya de que hoy usamos, mas otra historia de muy más alto estilo» (Los Cinco libros, ed. cit., p. 170, glosa). Piénsese que Pier Cándido Decembrio tradujo la Iliada de Homero del griego al latín entre 1439 y 1446, y que este la copió y dedicó a Juan II por mediación de Cartagena. Para todos estos asuntos, remito al ya clásico libro de Guillermo Serés, La traducción en Italia y España durante el siglo XV. La «Ilíada en romance» y su contexto cultural, Salamanca, Universidad, 1997, y a Pilar Saquero-Tomás González Rolán, «Sobre la presencia en España de la versión latina de la Ilíada de Pier Cándido Decembrio. Edición de la Vita Homeri y de su traducción castellana», en Cuadernos de Filología Clásica, 21 (1988), pp. 319-344. En 1431-1432, cuando Cartagena comienza a traducir a Séneca, aún se seguía conociendo la historia troyana a través de Dares y Dictis y de la popular obra de Guido della Colonne. No creo, pues, que en este comentario «se aluda a la versión de la Ilíada de Decembrio» (L. Fernández Gallardo, «Alonso de Cartagena y el humanismo», art. cit., p. 10, n. 14) y que, por ello, se deba datar la traducción de la Vita beata después de 1442.
} 
maneras se entiende en la escriptura, mas largamente se dirá en aquella tragedia, en el libro de las Tragedias Senece ${ }^{54}$

Además de temas ya recurrentes como el fingimiento de los poetas o el posible aprovechamiento de su obra, Cartagena insiste nuevamente en que, en las tragedias, Séneca «habla en ellas so nonbre de otros». Ya sabemos que nuestro autor lo había indicado «en otro lugar», concretamente en la glosa a «Asi lo creo» en la Breve copilaçión, que corresponde al Libro segundo de la edición impresa y que he tenido ocasión de reproducir más arriba. El Libro segundo antecede al primero, teniendo en cuenta que la redacción de la Copilaçión es anterior a la traducción del De providentia o Libro primero de la Providencia de Dios. Otra casuística muy diferente presentan los testimonios en que el Libro segundo se identifica con el De constantia sapientis, que no contiene ninguna reflexión sobre las tragedias comparable a la que hemos visto $^{55}$.

Todavía en este mismo libro y en esta misma glosa sobre Faetón, y siguiendo con su obsesión por individualizar responsabilidades, Cartagena nos enseña un método infalible y económico para diferenciar las palabras del autor y las del personaje, a través de una letra más oscura, a modo de negrita:

No hizo aquí mençión Séneca del sol ni de Fectón, mas continua la razón commo si fueran suyas las palabras. E por esto hazíase la letra más oscura. Por ende, púsose en el romançe qué dezía el sol a Fectón, porque el que lo leyere vea que no son palabras de Séneca, mas que son de otro actor e que las trahe a su propósito ${ }^{56}$

No son los Libros de la Providencia o las obras derivadas de la Tabulatio las únicas páginas en las que Cartagena reflexiona sobre todo aquello referido a las tragedias y a la esfera de lo dramático. En De la vida bienaventurada, previene:

${ }^{54}$ Los Cinco libros, p. 230. Introduzco la cursiva en las palabras finales, porque considero que Cartagena o la fuente de Cartagena se refiere a la obra latina. Así (Tragedias Senece) aparece en la biblioteca del Príncipe de Viana, según lo indica M. Menéndez y Pelayo, Bibliografia hispano-latina clásica, vol. VIII, Santander, CSIC, 1950-1953, p. 41. L. Fernández Gallardo («Tradición clásica», art. cit., p. 986), por el contrario, cree que se trata de una referencia a una traducción castellana. El problema es que no hay ningún dato objetivo que nos señale que antes de 1431 hubiese tal traducción de las Tragedias. Todo lo contrario sucede con el texto latino.

${ }^{55}$ Según la propuesta de N. G. Round, «Alonso de Cartagena», art. cit., pp. 129-132, la Copilaçion sería anterior al resto de tratados. A esta seguirían el Libro primero de la Providencia, el Libro segundo de la clemencia, el Libro primero de la clemencia, las Declamaciones y el Libro segundo de la Providencia [=De constantia sapientis $]$.

${ }^{56}$ Los Cinco libros, ed. cit., p. 229. 
contra el juego que nuevamente ahora se usa de los momos. Ca aunque de dentro déste está honestad y maduredad y gravedad entera, pero escandalízase quien ve hijosdaldo de estado CON VISAJES AJENOS, y creo que no lo usarían si supiesen de cuál vocablo latino desciende esta palabra momo ${ }^{57}$

Los momos, en efecto, eran frecuentes en el teatro cortesano, como pasatiempo o juego burlesco, ficción al cabo. Y justamente las ficciones, junto con las expansiones líricas, estuvieron ausentes del quehacer literario de nuestro autor $^{58}$. Conviene destacar el cambio peligroso que supone para Cartagena que las gentes de estado anden «con visajes ajenos», esto es, representando otras personas que no son, con la palabra, el gesto o la máscara. Aquellos que trastocaban el aspecto natural de la creación de Dios para convertirse en algo diferente y denigraban así su naturaleza humana merecían la condena de moralistas y predicadores. Pero precisamente la finalidad honesta podía limitar los excesos de los juegos y evitar que estos fuesen un fin en sí mismos, aunque ello solo era posible si este objetivo no resultaba ambiguo. Ejerciendo ese difícil equilibrio entre la crítica y el aprovechamiento, tan característico de Cartagena, este reconoce que detrás del juego de momos hay o puede haber «honestad y maduredad y gravedad entera». Creo no equivocarme si relaciono el paso con la eutrapelia ${ }^{59}$, la diversión honesta que incita a la virtud, que hay que vincular necesariamente con el ocio honesto del que habla en más de una ocasión el deán. Séneca se había referido a tal diversión en el De ira, en el De tranquilitate animi o en las Epistulae ad Lucilium $^{60}$. Qui-

${ }^{57}$ Ibídem, p. 97. En el Diccionario de Autoridades, se lee: «MOMO. s. m. Gesto, figurada, o mofa. Execútase regularmente para divertir en juegos, mogigangas y danzas. Díxose del Dios de la Gentilidad, assí llamado, porque se ocupaba en censurar ridiculamente, o hacer burla de las acciones de los demás Dioses. Latín. Momus. Mimus. CHRON. DEL R. D. JUAN EL II. cap. 263. E después de aquellos se hicieron danzas y momos». Lo consulto en línea, en $<$ http://web.frl.es/DA.html $>$, en el sitio de la RAE [Consulta: marzo 2018]. La insistencia sobre el engaño que produce el cambio de vestido y la ocultación de la cara es constante. Véase, por ejemplo, Alfonso de Palencia, Universal vocabulario en latín y en romance o Universale compendium vocabularum cum vulgari expositione, Hispali, Paulus de V Colonia cum suis sociis, 1490, f. CCLXXXI ra: «sunt mimi rerum humanarum imitatores qui [...] ludos scenicos celebriter atque peritissime peragebant induti vestibus persone quam imitari volebant conformibus velatisque faciebus [...]». Enlace: <http://www.cervantesvirtual.com/servlet/SirveObras/46872785767254386754491> [Consulta: octubre 2018].

${ }^{58}$ Como remarca Luis Fernández Gallardo a lo largo de La obra literaria de Alonso de Cartagena (1385-1456). Ensayo de historia cultural, Saarbrücken, Editorial Académica Española, 2012.

${ }^{59}$ Se refiere a ella la Tabulatio, en una glosa a la voz anima, que en catalán dice así: «Aristòtil en lo ·iiij - libre de les Ėtiques posa virtut la qual apella eutrapelia, a la qual assigna solaços e jochs; ço és a saber, que là hon hom és hugat de obres virtuoses e serioses e ordonades, sia recreat en jochs e $\cdot n$ solaços. Mas aquests jochs, segon[s] Tul·li en lo libre De officis deuen ésser honests e covinents».

${ }^{60}$ Ad Lucilium ep. 24, 13: «Quod vides accidere pueris, hoc nobis quoque maiusculis pueris evenit: illi quos amant, quibus assueverunt, cum quibus ludunt, si personatos vident, expavescunt: non hominibus tantum sed rebus persona demenda est et reddenda facies sua». 
zá se haya sobrevalorado un poco la influencia de los humanistas italianos sobre Cartagena en materias como estas, sin tener nada en cuenta el contacto de este con las páginas senequistas previo a sus traducciones ${ }^{61}$, encajadas la mayor parte en la franja cronológica que media entre dos viajes decisivos, a Portugal y a Basilea. Las reflexiones que los diálogos senequistas le pudieron provocar, debieron de impulsar el (re)planteamiento de ideas en el terreno ideológico, doctrinal y literario. Cartagena hubo de hablar del suicidio o del determinismo, pero también tuvo que acoplar tanto la interpretación de los mitos como la filosofía clásica a sus propios esquemas mentales y al ordenamiento de los de sus coetáneos. Y aquí cabría hablar, claro está, del concepto de tragedia que le llegó y de aquello que recuperó, si lo hubo, de gramáticos, filósofos y teólogos anteriores. En este sentido, se vio casi impelido a encontrar en algunas ficciones su sentido alegórico para no renunciar del todo a la herencia clásica. Las armas de la exégesis cristiana le abonaron sin duda el camino, metodológicamente hablando.

El futuro obispo de Burgos tuvo que dejar algún resquicio abierto para que no se juzgara negativamente toda representación, quizás teniendo en cuenta que dominicos y sobre todo franciscanos contribuyeron a consolidar la legitimidad de los espectáculos -de algunos espectáculos- como elemento de instrucción. Defender la bondad de tales actividades representaba un problema cuando la honestidad no era tan evidente o cuando los personajes no eran santos, mártires o figuras bíblicas, perfectamente imitables en su actitud y en su doctrina. Eso era lo que Cartagena no podía hacer con la tragedia clásica, a menos que hubiese apostado por introducir un gran cuerpo exegético para sobreponerse a la fuerza de la dicción de los personajes. Aquello que en el De providencia se podía salvar mediante glosas o cambios estratégicos ${ }^{62}$, no resultaría fácil de realizar en una traducción de las Tragedias.

Más que justificar las palabras de Cartagena a partir de las nociones de tragedia que circularon durante los siglos XIV y Xv, debemos considerar que su argumentación se basa en el desarrollo de los modi recitandi. En el prólogo general del comentario trevetiano, transcrito más arriba, ya se especificaba que, en el modus dramatis, no hablaba el poeta con voz propia, y que ese era concretamente el utilizado por Séneca en las Tragedias. Mucho antes,

\footnotetext{
${ }^{61}$ Sí que se ha hecho, por el contrario, con las traducciones ciceronianas, sobre todo a partir de la publicación de ediciones fiables, como la de María Morrás, Alonso de Cartagena. Libros de Tulio: De senetute, De los ofiçios, Alcalá de Henares, Universidad de Alcalá, 1996.

${ }^{62}$ Que por otra parte son recurrentes, como se comprueba leyendo la traducción catalana de la misma obra, en que reaparecen los mismos problemas doctrinales, Tomàs Martínez Romero, «Antoni Canals, Alonso de Cartagena unes notes de literatura comparada», en Medioevo romanzo, 20:1 (1996), pp. 116-146.
} 
Diomedes, en su Ars grammatica (III, 6), se había referido al modo Dramaticon vel activum, en el que «personae agunt solae sine ulla poete interlocutione ut se habent tragice vel comice fabule», al Exegeticon vel enarrativum $\mathrm{y}$ al Koinon vel commune, «in quo poeta ipse loquitur et persone loquentes introducitur ut est scripta Ilias vel Odysea ista tota Homeri» ${ }^{63}$. Esos ecos y los de Donato resuenan en Isidoro y más todavía en el De arte metrica de Beda el Venerable ${ }^{64}$. Evidentemente, Cartagena, como sus coetáneos, no pensaban en una tragedia representada, sino más bien leída o, en todo caso, recitada por uno o diversos personajes ${ }^{65}$. El género dramático se definía, pues, como una forma de narración en que el autor daba la palabra a otros (introducte persone) para que hablasen, independientemente de que su argumento fuese cómico o trágico, y de que la finalidad fuese imitativa, ejemplar, crítica o estilística. Esa concepción llegaba al siglo XV después de varias centurias de recorrido y se distinguía perfectamente de la estrategia seguida en la disputatio escolar, en que la transferencia de voz a otro ente tenía sentido en términos de dialéctica argumentativa.

Esa visión, vehiculada por autores escolares, doctores de la Iglesia y eruditos, venía sancionada además por teólogos y filósofos. En una de las 29 quaestiones disputatae contenidas en el De veritate, concretamente en el décimo artículo, Tomás de Aquino se planteaba si existía alguna cosa falsa ${ }^{66}$. En el quinto argumento, llega a relacionar verdadero y falso, puesto que si la falsedad existía en las cosas, únicamente podía tener algo verdadero como sujeto. Tomás recurre a San Agustín para mostrar que la falsedad se fundamenta en alguna verdad, sin ser lo mismo, y recurre al ejemplo de las tragedias:

unde dicit Augustinus in Lib. Soliloquiorum, quod TRAGOEDUS QUI REPRAESENTAT ALIENAS PERSONAS IN THEATRIS, non esset falsus [Hector], nisi esset verus tragoedus; similiter equus pictus non esset falsus equus, nisi esset

${ }^{63}$ Citado por P. Vescovo, «Dante e il "genere drammatico"», en Dante e l'arte, 1 (2014), pp. 45-66, p. 51. En un accessus a las Heroidas de Ovidio reportado por Minnis-Scott, se habla del modo exegemático (cuando habla el poeta), dramático (cuando hablan los personajes), y misticon o cinamicticon, (cuando hablan ambos, el poeta y los personajes). Evidentemente, cuando definían la tragedia, ni el autor del accessus ovidiano ni Cartagena pensaban en la poética aristotélica. Cfr. Medieval Literary Theory and Criticism c. 1100-c. 1375. The Commentary Tradition, ed. de A. J. Minnis y A. B. Scott with the assistance of D. Wallace, Oxford, Clarendon Press, 1991 (revised edition), p. 23.

${ }^{64}$ Vescovo, ibídem, p. 52: «Dramaticum est, vel activum, in quo personae loquentes introducuntur, sine poetae interlocutione, ut se habent tragoediae et fabulae».

${ }^{65}$ A. Kelly, ob. cit., pp. 193-194.

${ }^{66}$ No sé si esto desmiente en algo la afirmación de Villacañas en su «Introducción» a Los Cinco libros, ed. cit., p. 20: «De esta mentalidad conversa, con sus rasgos tradicionales y su sensibilidad para integrar lo nuevo, se derivan los supuestos centrales de Cartagena, no del escolasticismo ni del tomismo. Cartagena es, en este sentido, un hombre de acción, no un monje sutil». 
pura pictura. Nec tamen sequitur contradictoria esse vera, quia affirmatio et negatio, secundum quas dicitur verum et falsum, non referuntur ad idem ${ }^{67}$

El buen actor es capaz de representar a otra persona precisamente porque es verdadero, existe; esto es, si el personaje fuese verdadero, lo que resultaría falso sería el actor, puesto que no actuaría. La quaestio que santo Tomás disputaba en París hacia 1256 podía ir más allá de la dicotomía verdadero-falso en abstracto y plantearse en otros términos, como, por ejemplo, si aquello que decían los personajes era necesariamente lo que de verdad pensaba, no ya el actor, sino el mismo autor de la obra. En los Soliloquios (II, 10. 18) ${ }^{68}$, san Agustín aludía a Roscio, hombre en realidad, falsa Hécuba en escena: en tanto que Roscio, dentro de la ficción, representaba bien a la falsa Hécuba, era un verdadero actor trágico. Sin embargo, el nudo de la cuestión no era este, sino que, en tanto que falsedad, difícilmente se podía proponer su imitación. Roscio, en las tragedias, representaba alienas personas y, por ello, no se podía pretender que todo lo que decía o hacía en escena fuese lo que hubiera dicho o hecho el Roscio real en semejantes circunstancias. No muy lejos andaba, en fin, Juan Crisóstomo cuando criticaba a aquellos que se escondían tras las máscaras para representar aquello que no eran, fueran reyes, médicos o filósofos ${ }^{69}$. La máscara, la apariencia, la actuación, los alejaba por unos momentos de su propia existencia. Cartagena, por lo tanto, llegaba a un terreno muy abonado anteriormente, casi siempre en una dirección moral.

En la conocida Epístula al conde de Haro, nuestro autor-traductor hace referencia a los clásicos que, aunque gentiles, alentaban ad morum honestatem 2018].

${ }^{67}$ De veritate, q. 1 , a. 10 ad 5: <http://www.corpusthomisticum.org/qdv01.html> [Consulta: marzo

${ }^{68}$ PL 32, col. 893: «Quia scilicet aliud est falsum esse velle, aliud verum esse non posse. Itaque ipsa opera hominum velut comoedias aut tragoedias, aut mimos, et id genus alia possumus operibus pictorum fictorumque conjungere. Tam enim verus esse pictus homo non potest, quamvis in speciem hominis tendat, quam illa quae scripta sunt in libris comicorum. Neque enim falsa esse volunt, aut ullo appetitu suo falsa sunt; sed quadam necessitate, quantum fingentis arbitrium sequi potuerunt. At vero in scena Roscius voluntate falsa Hecuba erat, natura verus homo; sed illa voluntate etiam verus tragoedus, eo videlicet quo implebat, institutum: falsus autem Priamus, eo quod Priamum assimilabat, sed ipse non erat. Ex quo jam nascitur quiddam mirabile, quod tamen ita se habere nemo ambigit». Existen dos lugares clásicos de las Confesiones de san Agustín en los que se refiere al engaño en que se puede caer por la falsedad del teatro y de la mitología, si no se tiene plena consciencia de que se trata de invenciones: Conf. III, 2. 4: «At ego tunc miser dolore amabam, et quaerebam ut esset quod dolorem, quando mihi in aerumna aliena et falsa et saltatoria ea magis placebat actio histrionis meque alliciebat vehementius qua mihi lacrimae excutiebantur»; Conf. III, 6. 11: «nam versum et carmen etiam ad vera pulmenta transfero; volantem autem Medeam etsi cantabam, non adserebam, etsi cantari audiebam, non credebam» (Augustine, Confessions I, Introduction and Text, ed. de J. J. O'Donnell, Oxford, Clarendon Press, 1992, pp. 24 y 27). Véase también A. Kelly, ob. cit., p. 35.

${ }^{69}$ Lo cita M. Berthold, Historia social del teatro, Madrid, Ediciones Guadarrama, 1974, p. 192. 
y por ello eran susceptibles de leerse con eficacia. Si bien no eran ciertamente cristianos y no habían accedido a la verdad revelada, distinguían con claridad entre vicios y virtudes, por lo que, siguiendo el camino ya marcado por Basilio y Jerónimo, podían ser provechosos. En otra latitud se situaban los poetarum figmenta, capaces de llevarnos a la deshonestidad, por su contenido y estilo ${ }^{70}$. La prevención de Cartagena recuerda sin duda unas líneas del Decretum de Graciano ${ }^{71}$. En el grupo de las lecturas convenientes para los que pretenden acercarse a los libros de los gentiles, tampoco vale todo:

Et si libris gentilium uti delectat, illi querendi sunt qui ad morum honestatem alliciunt. Multi enim ex gentilibus fuerunt, qui licet fidem catholicam non receperint in moribus tamen honeste loquuntur, alii virtutes ac vicia scientifice designando, ut Plato et Aristoteles, alii ad virtutum sequellam et viciorum fugam suo clamore excitando, ut Cicero et Seneca aliquibus in libris fecerunt, licet in nonnullis locis aliquantulum aberrarunt, et si qui sunt alii per scientificum modum docendo vel per suavem stillum persuadendo de viciis ac virtutibus recte senserunt, quos enumerare esset perlongum ${ }^{72}$

Esto es, tanto Cicerón como Séneca escribieron páginas saludables al lado de otras que no siguen las condiciones exigidas. Jeremy Lawrance suponía que, en el caso de Séneca, la censura de Cartagena se dirigía hacia las Tragedias. Después de analizar sus ideas sobre la tragedia, no me cabe ninguna duda de que fue así.

Recibido: $31 / 05 / 2018$

Aceptado: 09/11/2018

\footnotetext{
${ }^{70}$ «A libris itaque illis abstinendum erit, qui ad inhonestatem videntur allicere, uti sunt amatoria, bucolica, aliaque poetarum figmenta, que, licet eloquenti stillo et acuta inventione composita sint, magnamque ingenii elevationem ostendent, cum mirabili compositione metrorum exquisitisque verbis coagulata dulcem saporem conficiant, in nonnullis tamen eorum materia obscaena et provocativa libidinum est» (J. N. H. Lawrance, Un tratado de Alonso de Cartagena sobre la educación y los estudios literarios, Bellaterra, Universitat Autònoma de Barcelona, 1979, p. 50).

${ }^{71}$ Pars I, d. 37, c. 15: «Ideo prohibetur Christianus figmenta legere poetarum, quia per oblectamenta inanium fabularum mentem excitant ad incentiva libidinum».

72 J.N.H. Lawrance, ob. cit., pp. 52-53.
} 


\title{
$\cos$
}

\author{
«No han AUCTORIDAD DE DOCTRINA»: Alfonso DE CARTAGENA \\ Y SUS IDEAS SOBRE LA TRAGEDIA Y SU TRANSMISIÓN
}

RESUMEN: Alfonso de Cartagena alude en alguna de sus glosas a la poca veracidad de los personajes y parlamentos de las tragedias e insiste en su debilidad como autoridades. Lo argumenta recurriendo a ideas -y prevenciones- que le llegan desde la literatura, la filosofía y la teología, y que provienen de una tradición anterior, que le sirve de fuente. En este artículo se realiza un recorrido por las bases teóricas que permitieron mostrar a Cartagena su particular punto de vista sobre el tema y se analiza el uso real que hizo de ellas en sus escritos y traducciones.

Palabras Clave: Tragedia en la Edad Media. Alfonso de Cartagena. Séneca trágico. Trevet.

\section{«No han AUCTORIDAd DE DOCTRINA»: Alfonso de CARTAGENA AND HIS IDEAS ABOUT THE TRAGEDY AND ITS TRANSMISSION}

\begin{abstract}
Alfonso de Cartagena makes reference in some of his glosses to the little veracity of the characters and dialogues in the tragedies, and insists that they lack strength as authorities. This argument is supported by recurring to ideas - and precautions - from literature, philosophy and theology, which come from an earlier tradition, also used as the source for his statements. In this article the basic theories that allowed Cartagena to form his particular view on the matter are covered. Furthermore, an analysis of the actual use he made of them in his writings and translations is featured.
\end{abstract}

KEYwORDS: Tragedy in the Middle Age. Alfonso de Cartagena. Seneca tragicus. Trevet. 